\title{
Intent, Action and Feedback: A Preparation for Teaching
}

NED A. FLANDERS

\section{The Problem}

The point is that much of what is learned in education courses is neither conceptualized, quantified, nor taught in a fashion that builds a bridge between theory and practice. Education students are only occasionally part of an exciting, systematic, exploration of the teaching process, most infrequently by the instructor's example. How can we create, in education courses, an active, problem-solving process, a true sense of inquiry, and a systematic search for principles through experimentation? At least one factor favors change and that is the lack of solid evidence that anything we are now teaching is clearly associated with any index of effective teaching, with the possible exception of practice teaching.

A great many factors resist curriculum change in teacher education. Perhaps the most important is that genuine curriculum innovation, to be distinguished from tinkering with content and sequence, would require that existing faculty members, old and new alike, think differently about their subject matter, act differently while teaching, and relate differently to their students. For some this is probably impossible, for all it would be difficult. Yet changes do occur when enough energy is mobilized and convictions are strongly held.

It is a serious indictment of the profession, however, to hear so many education instructors say that their students will appreciate what they are learning after they have had some practical teaching experience. What
Dr. Flanders is professor of education at the University of Michigan, Ann Arbor.

hurts is the obvious hypocrisy of making this statement and then giving a lecture on the importance of presenting material in such a way that the immediate needs and interests of the pupils are taken into consideration. Such instances reveal a misunderstanding of theory and practice. To be understood, concepts in education must be verified by personal field experiences; in turn, field experiences must be efficiently conceptualized to gain insight. With most present practices, the gorge between theory and practice grows deeper and wider, excavated by the very individuals who are pledged to fill it.

One stumbling block is our inability to describe teaching as a series of acts through time and to establish models of behavior which are appropriate to different kinds of teaching situations. This problem has several dimensions. First, in terms of semantics, we must learn how to define our concepts as part of a theory. We also need to organize these concepts into the fewest number of variables necessary to establish principles and make predictions. Too often we try to teach the largest number of variables; in fact, as many as we can think of for which there is some research evidence. Second, in terms of technology, we must develop procedures for quantifying the 
qualitative aspects of teaching acts so that our students will have tools for collecting empirical evidence. Third, in terms of philosophy, we must decide whether our education students are going to be told about teaching in lectures and read about it in books or if they are going to discover these things for themselves. This paper will be devoted to these three issues, in reverse order.

\section{A Philosophy of Inquiry}

When Nathaniel Cantor (5) published his nine assumptions of orthodox teaching, there was little evidence to support his criticisms. Must pupils be coerced into working on tasks? In what way is the teacher responsible for pupils' acquiring knowledge? Is education a preparation for later life rather than a present, living experience? Is subject matter the same to the learner as it is to the teacher? The last decade has provided more evidence in support of Cantor's criticism than it has in defense of existing practice.

H. H. Anderson and his colleagues $(1,2,3,4)$ first demonstrated that dominative teacher contacts create more compliance and resistance to compliance, that dominative teacher contacts with pupils spread to the pupil-topupil contacts even in the absence of the teacher, and that this pattern of teaching creates situations in which pupils are more easily distracted and more dependent on teacher initiative.

Flanders and Havumaki (8) demonstrated that dominative teacher influence was more persuasive in changing pupil opinions but that such shifts of opinion were not stable since inner resistance was so high.

A research team in Provo, Utah (9) believes that patterns of spontaneous teacher action can be identified and that more effective patterns can be distinguished from less effective patterns. The difference is that more dominative patterns are less effective.

Our own eight-year research program which involved the development of interaction analysis as a tool for quantifying patterns of teacher influence lends further support to Cantor. The generalizations to follow are based on all teachers observed in our different research projects. This total is only 147 teachers, representing all grade levels, six different school districts in two countries; but these teachers came from the extremes of a distribution involving several thousand teachers. The total bits of information collected by interaction analysis are well in excess of $1,250,000$.

The present, average domination of teachers is best expressed as the rule of two-thirds. About two-thirds of the time spent in a classroom, someone is talking. The chances are two out of three that this person is the teacher. When the teacher talks, two-thirds of the time is spent by many expressions of opinion and fact, giving some direction and occasionally criticizing the pupils. The fact that teachers are taking too active a part for effective learning is shown by comparing superior with less effective classrooms. A superior classroom scores above average on constructive attitudes toward the teacher and the classwork. It also scores higher on achievement tests of the content to be learned, adjusted for initial ability. In studies (7) of seventh grade social studies and eighth grade mathematics, it was found that the teachers in superior classrooms spoke only slightly less, say 50 to 60 per cent of the time, but the more directive aspects of their verbal influence went down to 40 to 50 per cent. These teachers were much more flexible in the quality of their influence, sometimes very direct, but on more occasions very indirect.

To describe the classrooms which were below average in constructive pupil attitudes and in content achievement (they are positively correlated), just change the rule of twothirds to the rule of three-fourths plus.

The foregoing evidence shows that no matter what a prospective teacher hears in an education course, he has, on the average, been exposed to living models of what teaching is and can be that are basically quite directive. After fourteen or so years he is likely to be quite dependent, expecting the instructor to tell him what to do, how to do it, when he is finished, and then tell him how well he did it. Now it is in this general context that we 
turn to the question of how we can develop a spirit of inquiry with regard to teaching.

Thelen (10) has described a model of personal inquiry, as well as other models, and the question is whether teacher education can or should move toward this model. He describes this model as follows (ibid., p. 89):

... (personal inquiry) is a process of interaction between the student and his natural and societal environment. In this situation the student will be aware of the process of which he is a part; during this process he will be aware of many choices among ways he might behave; he will make decisions among these ways; he will then act and see what happens; he will review the process and study it with the help of books and other people; he will speculate about it, and draw tentative conclusions from it.

Returning to the education course, the student will be aware of the learning process of that classroom, he will confront choices, he will make decisions among the choices, he will act and then evaluate his actions, and then he will try to make some sense out of it with the help of books, the instructor, and his peers. This is a tall order, but who knows, it may be the only route to discovery and independence for the prospective teacher.

Occasionally we hear of exciting learning experiences in which education students attain a sort of intellectual spirit of inquiry. A unit on motivation can begin with an assessment of the motivation patterns of the education students. The same assessment procedures can then be used at other grade levels, permitting comparisons and generalizations. Principles of child growth and development can be discovered by observation and learned more thoroughly, perhaps, than is possible with only lecture and reading. But this is not what is meant by inquiry.

Inquiry in teacher education means translating understanding into action as part of the teaching process. It means experimenting with one's own behavior, obtaining objective information about one's own behavior, evaluating this information in terms of the teacher's role; in short, attaining self-insight while acting like a teacher.

Procedures for obtaining self-insight have been remarkably improved during the last decade in the field of human relations training. Two characteristics of these training methods seem relevant to this discussion. First, information and insights about behavior must become available in a way that can be accepted and in a form that is understood. Second, opportunities to utilize or act out these insights must be provided. Our ability to accept information about ourselves is a complex problem, but it helps if we believe the information is objective, valid, and given in an effort to help rather than hurt. Our understanding of this information will depend a great deal on our ability to organize the information conceptually. Freedom to act at least requires freedom from threat or embarrassment.

From all of these things, a spirit of inquiry develops.

\section{The Technique of Interaction Analysis}

Interaction analysis is nothing more and nothing less than an observation technique which can be used to obtain a fairly reliable record of spontaneous verbal statements. Most teacher influence is exerted by verbal statements, and to determine their quality is to approximate total teacher influence. This technique was first developed as a research tool, but every observer we ever hired testified that the process of learning the system and using it in classrooms was more valuable than anything else he learned in his education courses. Since interaction analysis is only a technique, it probably could be applied to teacher education in a fashion that is consistent or even totally inconsistent with a philosophy of personal inquiry. How it is used in teacher preparation is obviously as important as understanding the procedure itself.

The writing of this manuscript followed the completion of a terminal contract report of a U.S. Office of Education-sponsored, inservice training program based on interaction analysis as a tool for gathering information. How we used interaction analysis is illustrated by the conditions we tried to create for the fifty-five participating teachers, most of whom 
represented about one-half of the faculties of two junior high schools: ${ }^{1}$

1) Teachers developed new (to them) concepts as tools for thinking about their behavior and the consequences of their behavior. These concepts were used to discover principles of teacher influence. Both types of concepts were necessary: those for describing actions and those for describing consequences.

2) Procedures for assessing both types of concepts in practical classroom situations were tried out. These procedures were used to test principles, to modify them, and to determine when they might be appropriately applied.

3) The training activities involved in becoming proficient in the assessment of spontaneous behavior, in and of themselves, increased the sensitivity of teachers to their own behavior and the behavior of others. Most important, teachers could compare their intentions with their actions.

4) By avoiding a discussion of right and wrong ways of teaching and emphasizing the discovery of principles of teacher influence, teachers gradually became more independent and self-directing. Our most successful participants investigated problems of their own choosing, designed their own plans, and arranged collaboration with others when this seemed advantageous.

Five filmstrips and one teacher's manual have been produced and written. These materials would have to be modified before they could be used with undergraduate students. Before asking how interaction analysis might be used in teacher preparation, we turn next to a description of the procedures.

\section{The Procedure of Observation}

The observer sits in a classroom in the best position to hear and see the participants. At the end of each three-second period, he decides which category best represents the com-

\footnotetext{
${ }^{1}$ Interaction analysis as a research tool has been used ever since R. F. Bales first developed a set of categories for studying groups. Most of our research results can be found in the references at the end of this paper. Its use as a training device is more recent. Projects have taken place in New Jersey, Philadelphia, Chicago, and Minneapolis. Systematic evaluation is available in only the Minneapolis project.
}

munication events just completed. He writes this category number down while simultaneously assessing communication in the next period and continues at a rate of 20 to 25 observations per minute, keeping his tempo as steady as possible. His notes are merely a series of numbers written in a column, top to bottom, so that the original sequence of events is preserved. Occasionally marginal notes are used to explain the class formation or any unusual circumstances. When there is a major change in class formation, the communication pattern, or the subject under discussion, a double line is drawn and the time indicated. As soon as the total observation is completed, the observer retires to a nearby room and completes a general description of each separate activity period separated by the double lines, including the nature of the activities, the class formation, and the position of the teacher. The observer also notes any additional facts that seem pertinent to an adequate interpretation and recall of the total visit.

The ten categories that we used for interaction analysis are shown in Table 1.

The numbers that an observer writes down are tabulated in a $10 \times 10$ matrix as sequence pairs, that is, a separate tabulation is made for each overlapping pair of numbers. An illustration will serve to explain this procedure.

Teacher: "Class! The bell has rung. May I have your attention please!'[6] During the next three seconds talking and noise diminish.[10]

Teacher: "Jimmy, we are all waiting for you." [7] Pause.

Teacher: "Now today we are going to have a very pleasant surprise, [5] and I think you will find it very exciting and interesting. [1] Have any of you heard anything about what we are going to do?" [4]

Pupil: "I think we are going on a trip in the bus that's out in front." [8]

Teacher: "Oh! You've found out! How did you learn about our trip?" [4]

By now the observer has written down 6 , $10,7,5,1,4,8$, and 4 . As the interaction proceeds, the observer will continue to write 


\begin{tabular}{|c|c|c|}
\hline Teacher & $\begin{array}{c}\text { Indirect } \\
\text { Influence }\end{array}$ & $\begin{array}{l}\text { 1.* Accepts Feeling: accepts and clarifies the feeling tone of the students in a nonthreatening } \\
\text { manner. Feelings may be positive or negative. Predicting or recalling feelings are in- } \\
\text { cluded. } \\
\text { 2.* Praises or Encourages: praises or encourages student action or behavior. Jokes that release } \\
\text { tension, not at the expense of another individual, nodding head or saying, "um hm?" or } \\
\text { "go on" are included. } \\
\text { 3.* Accepts or Uses Ideas of Student: clarifying, building or developing ideas suggested by a } \\
\text { student. As teacher brings more of his own ideas into play, shift to category five. } \\
\text { 4.* Asks Questions: asking a question about content or procedure with the intent that a student } \\
\text { answer. }\end{array}$ \\
\hline & $\begin{array}{c}\text { Direct } \\
\text { Influence }\end{array}$ & $\begin{array}{l}\text { 5.* Lecturing: giving facts or opinions about content or procedures; expressing his own ideas, } \\
\text { asking rhetorical questions. } \\
\text { 6. Giving Directions: directions, commands, or orders with which a student is expected to } \\
\text { comply. } \\
\text { 7.* Criticizing or Justifying Authority: statements intended to change student behavior from } \\
\text { nonacceptable to acceptable pattern; bawling someone out; stating why the teacher is } \\
\text { doing what he is doing; extreme self-reference. }\end{array}$ \\
\hline \multirow{2}{*}{\multicolumn{2}{|c|}{ Student Talk }} & 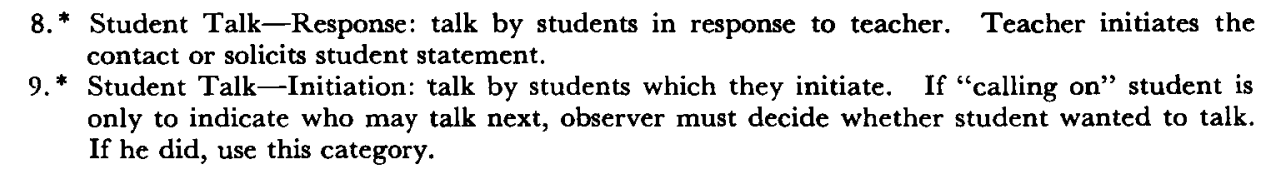 \\
\hline & & $\begin{array}{l}\text { 10. Silence or Confusion: pauses, short periods of silence and periods of confusion in which } \\
\text { communication cannot be understood by the observer. }\end{array}$ \\
\hline
\end{tabular}

* There is no scale implied by these numbers. Each number is classificatory; it designates a particular kind of communication event. To write these numbers down during observation is to enumerate, not to judge a position on a scale.

down numbers. To tabulate these observations in a $10 \times 10$ matrix, the first step is to make sure that the entire series begins and ends with the same number. The convention we use is to add a 10 to the beginning and end of the series unless the 10 is already pressent. Our series now becomes $10,6,10,7,5$, $1,4,8,4$, and 10 .

These numbers are tabulated in a matrix, one pair at a time. The column is indicated by the second number, the row is indicated by the first number. The first pair is 10-6; the tally is placed in row ten, column six cell. The second pair is 6-10; tally this in the row six, column ten cell. The third pair is 10-7, the fourth pair is 7-5, and so on. Each pair overlaps with the next, and the total number of observations, "N," always will be tabulated by $\mathrm{N}-\mathrm{l}$ tallies in the matrix. In this case we started a series of ten numbers, and the series produced nine tallies in the matrix.
Table 2 shows our completed matrix. Notice that in a correctly tabulated matrix the sums of the corresponding rows and columns are equal.

The problem of reliability is extremely complex, and a more complete discussion can be found in two terminal contract reports $(6,7)$ one of which will be published as a research monograph in the 1963 series of the Cooperative Research Program. Education students can learn how to make quick field checks of their reliability and work toward higher reliability under the direction of an instructor.

\section{The Interpretation of Matrices}

A matrix should have at least 400 tallies, covering about twenty minutes or more of a homogeneous activity period, before attempting to make an interpretation. 
TABLE 2

\begin{tabular}{|c|c|c|c|c|c|c|c|c|c|c|c|}
\hline Category & 1 & 2 & 3 & 4 & 5 & 6 & 7 & 8 & 9 & 10 & Total \\
\hline 1 & & & & 1 & & & & & & & 1 \\
\hline 2 & & & & & & & & & & & 0 \\
\hline 3 & & & & & & & & & & & 0 \\
\hline 4 & & & & & & & & 1 & & 1 & 2 \\
\hline 5 & 1 & & & & & & & & & & 1 \\
\hline 6 & & & & & & & & & & 1 & 1 \\
\hline 7 & & & & & 1 & & & & & & 1 \\
\hline 8 & & & & 1 & & & & & & & 1 \\
\hline 9 & & & & & & & & & & & 0 \\
\hline 10 & & & & & & 1 & 1 & & & & 2 \\
\hline Total & 1 & 0 & 0 & 2 & 1 & 1 & 1 & 1 & 0 & 2 & 9 \\
\hline
\end{tabular}

Certain areas within the matrix are particularly useful for describing teacher influence. Some of these areas will now be discussed by making reference to Table 3 .

The column totals of a matrix are indicated as Areas “A," “B," “C," and "D." The figures in these areas provide a general picture by answering the following questions: What proportion of the time was someone talking compared with the portion in which confusion or no talking existed? When someone was talking, what proportion of the time was used by the students? By the teacher? Of the time that the teacher talked, what proportion of his talk involved indirect influence? Direct influence?

The answers to these questions form a necessary backdrop to the interpretation of the other parts of the matrix. If student participation is about 30 or 40 per cent, we would expect to find out why it was so high by studying the matrix. If the teacher is particularly direct or indirect, we would expect certain relationships to exist with student talk and silence.

The next two areas to consider are areas " $E$ " and "F." Evidence that categories 1, 2, and 3 were used for periods longer than three seconds can be found in the diagonal cells, 1-1, 2-2, and 3-3. The other six cells of Area E indicate various types of transitions between these three categories. Sustained praise or clarification of student ideas is especially significant because such elaboration often involves criteria for praise or reasons for accepting ideas and feelings. The elaboration of praise or student ideas must be present if the student's ideas are to be integrated with the content being discussed by the class.

Area $\mathbf{F}$ is a four-cell combination of giving directions (category 6) and giving criticisms or self-justification (category 7 ). The transition cells 6-7 and 7-6 are particularly sensitive to difficulties that the teacher may have with classroom discipline or resistance on the part of students. When criticism follows directions or direction follows criticism, this means that the students are not complying satisfactorily. Often there is a high loading on the 6-9 cell under these circumstances. Excessively high frequencies in the 6-6 cell and 7-7 cells indicate teacher domination and supervision of the students' activities. A high loading of tallies in the 6-6 cell alone often indicates that the teacher is merely giving lengthy directions to the class.

The next two areas to be considered are Areas $G$ and $H$. Tallies in these two areas occur at the instant the student stops talking and the teacher starts. Area $G$ indicates those instances in which the teacher responds to the termination of student talk with indirect influence. Area $\mathrm{H}$ indicates those instances in which the teacher responds to the termination of student talk with direct influence. An interesting comparison can be made by contrasting the proportion $G$ to $H$ versus the proportion $\mathrm{A}$ to $\mathrm{B}$. If these two proportions are quite different, it indicates that the teacher tends to act differently at the instant a student stops talking compared with his overall average. Often this is a mark of flexible teacher influence.

There are interesting relationships between Area $E$ and Area $G$ and between Area $F$ and Area H. For example, Area G may indicate that a teacher responds indirectly to students at the instant they terminate their talk, but 
an observer may wish to inspect Area $\mathrm{E}$ to see if this indirect response is sustained in any way. The same question with regard to direct influence can be asked of Areas $F$ and $H$. Areas $G$ and $H$ together usually fascinate teachers. They are often interested in knowing more about their immediate response to student participation.

Area I indicates an answer to the question, What types of teacher statements trigger student participation? Usually there is a high tally loading in cells 4-8 and 4-9. This is expected because students often answer questions posed by the teacher. A high loading on 4-8 and 8-4 cells alone usually indicates classroom drill directed by the teacher. The contrast of tallies in columns 8 and 9 in this area gives a rough indication of the frequency with which students initiate their own ideas versus respond to those of the teacher.

Area $I$ is often considered in combination with Area J. Area J indicates either lengthy student statements or sustained student-to- student communication. An above-average frequency in Area $\mathrm{C}$, but not in Area J, indicates that short answers, usually in response to teacher stimulation, have occurred. One would normally expect to find frequencies in Area $\mathrm{E}$ positively correlated with frequencies in Area J.

We turn next to concepts and principles of teacher influence before speculating about how this technique can be applied to teacher education.

\section{Concepts and Principles of Teacher Influence}

It may be too early to determine what are the fewest number of concepts which, if organized into logically related principles, can be used by a teacher to plan how he will use his authority. Surely he will need concepts that refer to his authority and its use. He will need concepts to describe learning goals and pupil tasks. He will need concepts to classify

TABLE 3

MATRIX ANALYSIS

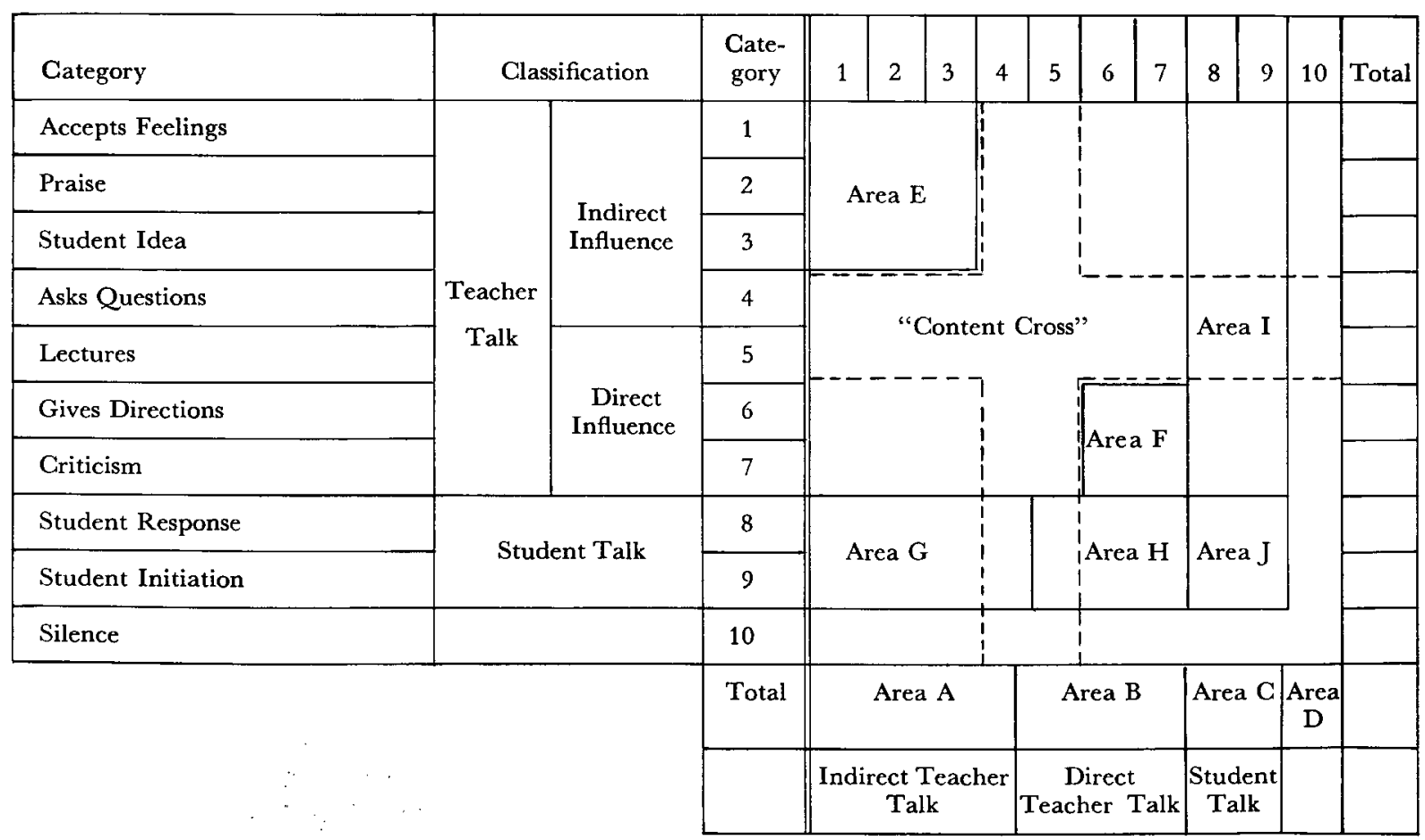


the responses of students. He may also need concepts to characterize class formations and patterns of classroom communication. These concepts are at least the minimum.

\section{Concepts That Refer to Teacher Behavior}

Indirect influence:-Indirect influence is defined as actions taken by the teacher which encourage and support student participation. Accepting, clarifying, praising, and developing the ideas and feelings expressed by the pupils will support student participation. We can define indirect behavior operationally by noting the per cent of teacher statements falling into categories $1,2,3$, and 4 .

Direct influence:-This concept refers to actions taken by the teacher which restrict student participation. Expressing one's own views through lecture, giving directions, and criticizing with the expectation of compliance tend to restrict pupil participation. We can define direct behavior operationally by noting the per cent of teacher statements falling into categories 5, 6, and 7 .

Other concepts which we do not have the space to discuss include: flexibility of teacher influence, dominance or sustained direct influence, and intervention.

\section{Concepts That Refer to Learning Goals}

Clear goals:-Goal perceptions are defined from the point of view of the pupil, not the teacher. "Clear goals" is a state of affairs in which the pupil knows what he is doing, the purpose, and can guess at the first few steps to be taken. It can be measured by paper-andpencil tests, often administered at different points in a problem-solving sequence.

Ambiguous goals:-“Ambiguous goals" describes a state of affairs in which a pupil is not sure of what he is expected to do, is not sure of the first few steps, or is unable to proceed for one reason or another. It can be measured as above.

Other concepts in this area include: attractive and unattractive clear goals, pupil tasks, task requirements, and similar concepts.

\section{Concepts That Refer to Pupil Responses}

Dependent acts:-Acts of dependence occur when a pupil not only complies with teacher influence but solicits such direction. A pupil who asks a teacher to approve of his work in order to make sure that it is satisfactory, before going on to the next logical step, is acting dependently. This type of response can be measured by observation techniques and by paper-and-pencil tests on which he indicates what kind of help he would like from the teacher.

Independent acts:-Acts of independence occur when the pupils react primarily to task requirements and are less directly concerned with teacher approval. The measurement of this concept is the same as for dependent acts.

Other concepts include: dependence proneness-a trait, compliance, conformity, counterdependence, and similar concepts.

\section{Some Principles That Can Be Discovered}

We discovered in our research (7) that, during the first few days of a two-week unit of study in seventh grade social studies and when introducing new material in eighth grade mathematics, superior teachers (as previously defined, page 252) are initially more indirect, becoming more direct as goals and associated tasks become clarified. We also suspect that these same teachers are more indirect when helping pupils diagnose difficulties, when trying to motivate pupils by arousing their interest, and in other situations in which the expression of pupil perceptions is helpful. On the other hand, the average or below average teacher did exactly the opposite.

Now the problem in teacher education is not only to create a situation in which education students could verify these relationships but could practice controlling their own behavior so as to become indirect or more direct at will. One place to begin is to have two, six-man groups work on a task under the direction of a leader. One task is something like an assembly line; it has a clear end product and sharp role differentiation. The other task is much more difficult to describe and 
does not have clear role differentiation. Now let the class superimpose different patterns of leader influence. Let them interview the role players, collect interaction analysis data by some simplified system of categories, and discuss the results. When undergraduate students first try to classify verbal statements, it sometimes helps to use only two or three categories. In one instance, the issue was the effect of using broad questions versus narrow questions. A broad question was one to which it was hard to predict the type of answer. A narrow question was one to which it was easy to guess at the type of answer. Which type of question was more likely to increase pupil participation? The students role-played this and kept a record of broad questions, narrow questions, and the length of the response. The fact that they verified their prediction correctly for this rather superficial problem was much less important compared with the experience that they gained. They learned how to verify a prediction with empirical evidence, and some had a chance to practice control of their own behavior for professional purposes.

There is no space here to list a complete set of principles that can be investigated by systematic or intuitive data-collecting procedures. The following questions might stimulate useful learning activities. Does dependence always decrease as goals become clear? Is the final level of dependence determined by the pattern of teacher influence when goals are first formulated? Are measures of content achievement related to the pupils' attitudes toward the teacher and the schoolwork? What effects can you expect from excessive and pedantic clarification of pupil ideas and feelings? And many others.

\section{Applications of Interaction Analysis to Teacher Education}

Suppose that before education students were given their practice teaching assignment, they had been exposed to a variety of data-collecting techniques for assessing pupil perceptions, measuring achievement, and quantifying spontaneous teacher influence. Suppose, further, that these skills had been taught in a context of personal inquiry as described earlier. What effect would this have on their approach to practice teaching?

One of their suggestions might be that two students should be assigned as a team to the first assignment. While one took over the class the other could be collecting information; the next day or so, the roles could be reversed. Together they would work out a lesson plan, agree on the data to be collected, go over the results with the help of the supervising teacher who might also have the same data-collecting skills. This situation could approach the inquiry model described earlier. The practice teacher might discover that his failure to clarify the pupils' ideas restricted the development of curiosity or that his directions were too short when he was asked for further help; both of these inferences can be made from an interaction matrix with reasonable reliability and objectivity.

Later on a student may wish to take a practice teaching assignment by himself and turn to the supervising teacher for aid in feedback. In either case, the requirement is that the learner be able to compare his intentions with feedback information about his actions and analyze this information by using concepts which he found useful in his earlier courses in education.

There are some precautions that can already be stated with regard to the use of interaction analysis in such a situation.

First, no interaction analysis data should be collected unless the person observed is familiar with the entire process and knows its limitations.

Second, the questions to be answered by inspecting the matrix should be developed before the observation takes place.

Third, value judgments about good and bad teaching behavior are to be avoided. Emphasis is given to the problem being investigated so that cause-and-effect relationships can be discovered.

Fourth, a certain amount of defensive behavior is likely to be present at the initial consultation; it is something like listening to a tape recording for the first time. 
Fifth, a consultation based on two observations or at least two matrices helps to eliminate value judgments or at least control them. Comparisons between the matrices are more likely to lead to principles.

Just how experiences of the type we have been discussing will fit into the present curricula is difficult to know. If activities of the sort described in this paper are valuable, are they to be superimposed on the present list of courses or is more radical surgery necessary?

Perhaps this is the point to risk a prediction, which is that teacher education will become increasingly concerned with the process of teaching itself during the next few decades. Instead of emphasizing knowledge which we think teachers will need in order to teach effectively, as we have in the past, we will turn more and more to an analysis of teaching acts as they occur in spontaneous classroom interaction. We are now at the point in our technology of data collecting at which procedures for analyzing and conceptualizing teaching behavior can be developed. Systems for doing this will become available regardless of whether they are similar or dissimilar to the procedures described in this paper. When this fine day arrives, the role of the education instructor will change, and the dichotomy between field and theory will disappear. The instructor's role will shift from talking about effective teaching to the rigorous challenge of demonstrating effective teaching. The process of inquiry will create problem-solving activities that will produce more independent, self-directing teachers whose first day on the job will be their worst, not their best.

These changes will be successful to the extent that the graduates of teacher education can learn to control their own behavior for the professional purpose of managing effective classroom learning. It will be the responsibility of the education instructor to help prospective teachers discover what their teaching intentions should be and then create training situations in which behavior gradually matches intentions with practice. Teaching will remain an art, but it will be studied scientifically.

\section{REFERENCES}

1. Anderson, Harold $H$. "The Measurement of Domination and of Socially Integrative Behavior in Teachers' Contacts with Children." Child Development 10: 73-89; June 1939.

2. - - , and Brewer, Helen M. Studies of Teachers' Classroom Personalities, I: Dominative and Socially Integrative Behavior of Kindergarten Teachers. Applied Psychology Monographs of the American Psychological Association. No. 6. Stanford, California: Stanford University Press, July 1945.

3. - - - , and Brewer, Joseph E. Studies of Teachers Classroom Personalities, II: Effects of Teachers' Dominative and Integrative Contacts on Children's Classroom. Behavior. Applied Psychology Monographs of the American Psychological Association. No. 8. Stanford, California: Stanford University Press, June 1946.

4. --_-; Brewer, J. E.; and Reed, M. F. Studies of Teachers' Classroom Personalities, III: Follow-up Studies of the Effects of Dominative and Integrative Contacts on Children's Behavior. Applied Psychology Monographs of the American Psychological Association. No. 11. Stanford, California: Stanford University Press, December 1946.

5. Cantor, Nathaniel, The Teaching-Learning Process. New York: Dryden Press, 1953. pp. 59-72.

6. Flanders, N. A. A terminal contract report on using interaction analysis for the inservice training of teachers. To be submitted to the U.S. Office of Education, N.D.E.A., Title VII. Available from the author, University of Michigan, after April 1963.

7. - - - Teacher Influence, Pupil Attitudes, and Achievement. Dittoed manuscript to be published in 1963 as a Research Monograph, Cooperative Research Program, U.S. Office of Education. Available from author, University of Michigan, 1962. $176 \mathrm{pp}$.

8. - - , and Havumaki, S. "Group Compliance to Dominative Teacher Influence." Human Relations 13:67-82.

9. Romney, G. P.; Hughes, M. M.; and others. Progress Report of the Merit Study of the Provo City Schools. Provo, Utah, August 1958. XIX $+226 \mathrm{pp}$. See also Patterns of Effective Teaching: Second Progress Report of the Merit Study of the Provo City Schools. Provo, Utah, June 1961. XII + 93 pp.

10. Thelen, H. A. Education and the Human Quest. New York: Harper Brothers, 1960. pp. 74-112.

Bad debts are proving to be "astonishingly small" under the federally sponsored loan program for college students. U.S. Commissioner of Education Francis Keppel told a House appropriations subcommittee only $\$ 700$ of the $\$ 218$ million lent to students after the program began in 1959 and up to June 30 last year had been written off as uncollectible. More than 37,000 students were repaying their loans, he said.-Education U.S.A., Washington, D.C.; April 25, 1963. 